RESEARCH REPORT

\title{
Intimate partner violence among Canadian women with activity limitations
}

\author{
Marsha M Cohen, Tonia Forte, Janice Du Mont, llene Hyman, Sarah Romans
}

J Epidemiol Community Health 2005;59:834-839. doi: 10.1136/jech.2004.022467

\begin{abstract}
See end of article for authors' affiliations

....................

Correspondence to: Dr M M Cohen, Centre for Research in Women's Health, 790 Bay Street, 7th Floor, Toronto, Ontario, Canada M5G 1N8; mmcohen@istar.ca

Accepted for publication 22 October 2004
\end{abstract}

\begin{abstract}
Objective: To determine the prevalence of intimate partner violence (IPV) in the previous five years among women reporting activity limitations (AL).

Design and setting: A community based, representative telephone survey of Canadians aged 15 and over. AL was assessed by the question: "Does a long term physical or mental condition or health problem reduce the amount or the kind of activity that you can do at home, at school, at work or in other activities?" Response categories were: often, sometimes, or never.

Participants: 8771 women who had a current/former partner of whom 1483 reported AL.

Main results: IPV was reported more often for AL (offen or sometimes) compared with no AL women (emotional abuse (27.1, 26.4 v 17.7\%, $\mathrm{p}<0.0001)$, physical-severe $(7.3,6.7 \vee 3.6 \%, \mathrm{p}<0.0001$ ), sexual abuse $(3.5,3.6 \vee 1.4 \%, \mathrm{p}<0.0001))$, or any IPV $(30.5,27.8 v 19.6 \%, \mathrm{p}<0.0001)$. Adjusting for age, marital status, education, income, employment, children in the household, Aboriginal or visible minority status, place of birth, urban or rural residence, region of Canada, time in current residence, and religious attendance, $\mathrm{AL}$ women had higher odds of IPV ladjusted odds ratio: $\mathrm{AL}$ often $=2.12 ; 95 \% \mathrm{Cl}$ : 1.64, 2.74; $\mathrm{AL}$ sometimes: $\mathrm{OR}=1.64 ; 95 \% \mathrm{Cl}: 1.40,2.29)$.

Conclusion: These findings call for increased recognition of violence that occurs in the lives of women with AL. This community based study suggests that abuse among those reporting $A L$ is high. Women with $A L$ represent a high risk group to be targeted in terms of IPV prevention and intervention.
\end{abstract}

r timate partner violence (IPV), has only recently been recognised as a risk factor for poor physical and mental health. ${ }^{1-4}$ To understand the relation between abuse and health, IPV needs to be quantified and described more adequately so that interventions can be effectively focused. It is important to identify whether specific groups are at increased risk of IPV and consequently of poorer health.

Women with disabilities seem to be at high risk for abuse. The vulnerability of disabled populations to abuse is thought to be attributable to increased physical and economic dependence on others. ${ }^{5}$ Other factors may include lower risk of discovery as perceived by the perpetrator, difficulty in being believed, less education about sexuality, social isolation, physical helplessness, and societal attitudes towards the disabled. ${ }^{6}$

The definition of disability includes a wide variety of health conditions, both stable (for example, paraplegic) and progressive (for example, heart disease). Nosek et al defined disability as physical (injury, chronic disease, or congenital conditions), sensory (hearing or visual), or mental (developmental, cognitive, or mental illness) impairments. Recently, the World Health Organisation recognised a broader view of disability in its International Classification for Functioning, Disability and Health (ICF). ${ }^{7}$ The ICF considers health and disability as a continuum. The classification system emphasises health and functioning, acknowledging that virtually every person will experience some decrement in health during the life span. Disability encompasses impairments in body functions, limitations in activities, and restrictions in social participation. An activity is the "execution of a task or action taken by an individual"; and activity limitations are "difficulties an individual may have in executing activities". In this study, the term activity limitations (AL) is used rather than disability.

In this study, our goal was to provide better estimates of the prevalence of IPV among women with AL as compared with women without AL using data from a large population based, national, representative sample. As women with AL probably differ from women in the general population (for example, they may be older), we also considered whether sociodemographic characteristics influenced the estimates of the risk of IPV for women with AL.

\section{METHODS}

After receiving institutional ethics committee approval, we undertook an analysis of the 1999 general social survey (GSS), a Canadian national, cross sectional, voluntary telephone survey conducted by Statistics Canada. ${ }^{8}$ In 1999, cycle 13 focused on violence and victimisation. ${ }^{9}$

The target population was aged 15 years and over, living in private households in the 10 Canadian provinces. The sample was selected using a method of random digit dialling, the elimination of non-working banks. ${ }^{8}$ After a household was contacted, one eligible person was randomly selected to be interviewed using computer assisted telephone interviewing. Interviews (in English or French) were carried out in February to December 1999. Exclusions were: no telephone, not speaking French or English, living in institutions, living in the Northern Territories, being homeless, or not capable of completing the survey (for any reason including cognitive limitations). The overall response rate for the survey was $81.3 \%$. The total sample consisted of 25876 respondents.

\section{Activity limitation (AL)}

The GSS assessed AL by asking: Does a long term physical or mental condition or heath problem reduce the amount or the kind of activity that you can do at home, at school, at work or in other activities?-where long term was considered to be at

Abbreviations: IPV, intimate partner violence; $\mathrm{AL}$, activity limitations; GSS, general social survey 
least six months. Response categories included often, sometimes, or never.

\section{Intimate partner violence (IPV)}

This analysis focused on IPV to women by a current or former partner within the previous five years from the date of the survey. Respondents reporting former partners must have had contact within the previous five years.

In the GSS, physical and sexual IPV were measured using a modified version of the conflicts tactics scale (CTS)..$^{10}$ The CTS is commonly used in family violence surveys and has been shown to have good internal consistency and validity. ${ }^{11}$ Respondents were asked to think of situations when they engaged in particular acts with their current or former partner and to indicate how often they engaged in these acts. Respondents answered yes or no to individual items measuring physical and sexual abuse. Physical abuse was assessed by asking respondents whether a current or former partner threatened to hit them, threw something at them, pushed, grabbed, shoved or slapped (categorised as nonsevere violence), kicked, bit or hit, hit with something, beat up, choked, burned/scalded, or used or threatened with knife

Table 1 Sociodemographic characteristics of women reporting contact with a current or former partner in the previous five years in the 1999 general social survey, by level of activity limitation (weighted number and \%)

\begin{tabular}{|c|c|c|c|c|c|c|c|}
\hline \multirow[b]{2}{*}{ Characteristic } & \multicolumn{2}{|l|}{ AL often } & \multicolumn{2}{|c|}{ AL sometimes } & \multicolumn{2}{|l|}{ No AL } & \multirow[b]{2}{*}{$p$ Value } \\
\hline & Number & (\%) & Number & (\%) & Number & (\%) & \\
\hline \multicolumn{8}{|l|}{ Age group (years) } \\
\hline 15 to 24 & 22 & (5.1) & 22 & $(5.2) \dagger$ & 376 & (89.7) & $<0.0001$ \\
\hline 25 to 34 & 50 & (2.7) & 106 & (5.7) & 1697 & (91.6) & \\
\hline 35 to 44 & 135 & (5.5) & 176 & (7.3) & 2119 & (87.2) & \\
\hline 45 to 54 & 146 & (7.8) & 149 & (8.0) & 1580 & (84.3) & \\
\hline 55 to 64 & 167 & (14.2) & 136 & (11.6) & 873 & (74.2) & \\
\hline 65 and older & 214 & (21.0) & 162 & (15.9) & 643 & (63.1) & \\
\hline \multicolumn{8}{|l|}{ Marital status } \\
\hline Common law & 57 & (5.4) & 70 & (6.6) & 935 & (88.0) & $<0.0001$ \\
\hline Widowed & 34 & (24.7) & 20 & (14.8) & 83 & (60.6) & \\
\hline Divorced/separated & 79 & (13.4) & 66 & (11.2) & 445 & (75.4) & \\
\hline Single & 35 & (9.5) & 39 & $(10.8)$ & 292 & $(79.8)$ & \\
\hline Married & 523 & (8.0) & 552 & (8.4) & 5506 & (83.7) & \\
\hline \multicolumn{8}{|l|}{ Highest level education } \\
\hline University/college & 264 & (6.2) & 296 & $(7.0)+$ & 3672 & (86.8) & $<0.0001$ \\
\hline High school & 181 & (6.7) & 232 & (8.6) & 2286 & (84.7) & \\
\hline Some secondary/elementary/no schooling & $g 281$ & (16.0) & 216 & (12.3) & 1258 & (71.7) & \\
\hline \multicolumn{8}{|l|}{ Household income } \\
\hline No income- $\$ 29999$ & 251 & $(15.0)$ & 218 & $(13.0) \dagger$ & 1208 & (72.1) & $<0.0001$ \\
\hline$\$ 30000-\$ 49999$ & 154 & $(7.8)$ & 160 & $(8.1)$ & 1656 & (84.1) & \\
\hline$\$ 50000$ or more & 148 & (4.4) & 202 & (6.1) & 2990 & (89.5) & \\
\hline Unknown & 180 & (10.1) & 172 & (9.6) & 1433 & (80.3) & \\
\hline \multicolumn{8}{|l|}{ Main source of income } \\
\hline Employment or self employment & 199 & (3.7) & 344 & (6.4)† & 4874 & (90.0) & $<0.0001$ \\
\hline Other sources* ${ }^{*}$ & 398 & (19.7) & 297 & $(14.7)$ & 1329 & (65.7) & \\
\hline No income & 112 & (10.7) & 84 & (8.0) & 852 & (81.3) & \\
\hline Born in Canada & 617 & (8.8) & 625 & (8.9) & 5777 & (82.3) & 0.01 \\
\hline Aboriginal & 26 & (13.8) & 21 & (11.1) & 143 & (75.1) & 0.01 \\
\hline Visible minority & 31 & (4.3) & 45 & (6.2) & 653 & $(89.5)$ & $<0.001$ \\
\hline \multicolumn{8}{|l|}{ Years living in current dwelling } \\
\hline$<5$ & 264 & (7.2) & 294 & (8.0) & 3104 & (84.8) & $<0.01$ \\
\hline$\geqslant 5$ & 469 & (9.2) & 457 & (9.0) & 4169 & (81.8) & \\
\hline \multicolumn{8}{|l|}{ Religious attendance } \\
\hline At least once a week & 219 & (10.1) & 208 & (9.6) & 1741 & (80.3) & 0.05 \\
\hline At least once a month & 67 & (6.6) & 73 & (7.2) & 874 & (86.2) & \\
\hline Few times a year & 148 & (8.2) & 160 & (8.8) & 1504 & (83.0) & \\
\hline At least once a year & 52 & (8.1) & 49 & (7.7) & 539 & (84.2) & \\
\hline Not at all/never & 177 & (9.3) & 171 & (8.9) & 1565 & (81.8) & \\
\hline \multicolumn{8}{|l|}{ Number children aged 0-14 in household } \\
\hline None & 597 & $(10.8)$ & 558 & $(10.1) \dagger$ & 4396 & (79.2) & $<0.0001$ \\
\hline One & 66 & (4.7) & 88 & (6.3) & 1254 & (89.1) & \\
\hline Two & 54 & (4.2) & 71 & (5.5) & 1174 & (90.4) & \\
\hline Three or more & 16 & (3.1) & 34 & (6.7) & 462 & (90.3) & \\
\hline \multicolumn{8}{|l|}{ Region } \\
\hline Atlantic region & 81 & (11.4) & 59 & $(8.2) \dagger$ & 572 & (80.4) & $<0.0001$ \\
\hline Quebec & 227 & (10.0) & 134 & (5.9) & 1912 & (84.2) & \\
\hline Ontario & 230 & (7.2) & 323 & (10.1) & 2648 & (82.7) & \\
\hline Prairie region & 112 & (7.7) & 140 & (9.6) & 1207 & (82.7) & \\
\hline British Columbia & 84 & (7.4) & 96 & (8.5) & 948 & (84.1) & \\
\hline Urban residence & 573 & (8.5) & 568 & (8.4) & 5582 & (83.1) & 0.56 \\
\hline \multicolumn{8}{|l|}{ Number household members receiving } \\
\hline No other member & 38 & (7.8) & 53 & (10.8) & 399 & (81.4) & 0.74 \\
\hline One member & 497 & (7.9) & 510 & (8.1) & 5303 & (84.1) & \\
\hline Two members & 59 & (7.5) & 72 & (9.1) & 658 & (83.3) & \\
\hline Three members or more & 33 & (7.9) & 31 & (7.3) & 361 & (84.8) & \\
\hline Language of interview & & & & & & & \\
\hline English & 515 & (7.8) & 615 & (9.3) & 5509 & (83.0) & 0.0001 \\
\hline French & 218 & (10.2) & 136 & (6.4) & 1777 & (83.4) & \\
\hline
\end{tabular}


or gun (categorised as severe violence). Sexual abuse was assessed by asking respondents: Has your partner or former partner forced you into any unwanted sexual activity by threatening you, holding you down, or hurting you in some way?

Emotional abuse was defined if a respondent answered affirmatively to at least one statement about her partner/ former partner's behaviour: limited contact with family or friends, put you down or called you names to make you feel bad, was being jealous and didn't want you to talk to other men/women, harmed, or threatened to harm, someone close to you, demanded to know with whom you were and where you were at all times, and damaged or destroyed your possessions or property. ${ }^{9}$ Financial abuse was defined by the question: Has your partner prevented you from knowing about or having access to the family income, even if you asked?'

In this study, we examined each type of abuse separately (physical (non-severe and severe), sexual, emotional, and financial) and, for some analyses, we examined their combined effect (reporting at least one type of abuse was termed "any IPV").

\section{Sociodemographic variables}

We examined differences in sociodemographic factors between women with AL often, sometimes and never. Sociodemographic factors examined included age (10 year age groups), marital status (single, married, common law partner, divorced/separated, widowed), education (elementary, high school, university/college), household income (1999 Canadian dollars), main source of income (employment, benefits), number of household members receiving income, presence of children 14 years or younger in the household, ethnicity (Aboriginal or visible minority status), place of birth (Canada compared with other countries), urban or rural residence, region of Canada, years living in current dwelling, religious attendance, and language of survey interview.

\section{Statistical analysis}

All analyses were conducted using the Public Use Microdata File (Main File) from Statistics Canada. All analyses were weighted according to Statistics Canada's guidelines. ${ }^{12}$ For most variables, the proportion of missing values was less than $1 \%$ and the missing records were omitted. However, for household income, the proportion of missing records was about 20\%. Thus household income (1999 Canadian dollars) was categorised into four subgroups $<\$ 30000$ or no income, $\$ 30-50000$, more than $\$ 50000$, and unknown.

For sociodemographic characteristics, we compared women reporting AL often with those reporting AL sometimes and we compared women reporting any AL (sometimes or often) with those reporting no AL. We also compared groups in the proportion reporting physical, sexual, emotional, and financial IPV by a current or former partner in the previous five years. Among women reporting at least one type of IPV, we examined the proportion reporting the various types of abuse ( $\chi^{2}$ test for categorical variables).

We next determined the association between respondents' sociodemographic characteristics and any IPV using the $\chi^{2}$ test. Variables that were significantly associated with the outcome at the $\mathrm{p}<0.25$ level in a bivariate analysis were included in a multivariable model. We used a weighted multivariable logistic regression analysis to assess the risk of experiencing any IPV among women with AL often and sometimes compared with women with no AL after adjusting for sociodemographic characteristics. The model was checked for collinearity. The Hosmer-Lemeshow statistic on an unweighted model was used to assess goodness of fit and the c-statistic was used to calculate the discrimination of the model. A p value of 0.05 was considered significant and all tests of significance were two tailed. Analyses were conducted using Stata, version 7.0.

\section{RESULTS}

Among the 25876 respondents in the GSS, 14269 were women. Data were available on AL for 13491 women and of these, 8771 had a current or former partner with whom they had contact within the previous five years. Of the 8771 respondents with a current or former partner, 770 (8.8\%) reported having an AL often and 751 (8.6\%) reported having an AL sometimes. Only $6.7 \%$ of the sample reported IPV from both a current and a former partner in the previous five years.

Overall, there were some differences in sociodemographic characteristics between women who reported AL often and women who reported AL sometimes (table 1). Women reporting AL often were older $(p=0.001)$, had less education $(\mathrm{p}=0.005)$, had a lower income $(\mathrm{p}=0.05)$, were less likely to be employed $(p<0.0001)$, had fewer children 14 years of age or younger living in the household $(p=0.01)$, and were more likely to live in the Atlantic region $(\mathrm{p}<0.0001)$. There were no statistically significant differences for other socioeconomic factors. Most survey interviews were conducted in English.

We also saw differences in sociodemographic characteristics between women reporting AL (often or sometimes) and women reporting no AL (table 1). Women with AL were more likely to be older, not married, and had less education than women with no $\mathrm{AL}(\mathrm{p}<0.001)$. In addition, those with $\mathrm{AL}$ reported lower income and were more likely to receive income from sources other than employment compared with women with no AL. With respect to ethnicity, women with AL were more likely to have been born in Canada, to be Aboriginal, and were less likely to be from a visible minority group. Women with AL were more likely to have lived at their current dwelling for five or more years, reported more frequent religious attendance, and were less likely to have young children in the household. There was no difference between those with $\mathrm{AL}$ and those without $\mathrm{AL}$ in region of

Table 2 Weighted prevalence of physical, sexual, emotional, and financial abuse among women reporting contact with a current or former partner in previous five years in the 1999 general social survey, by level of activity limitation

\begin{tabular}{|c|c|c|c|c|c|c|c|}
\hline \multirow[b]{2}{*}{ Type of IPV } & \multicolumn{2}{|l|}{ AL often } & \multicolumn{2}{|c|}{ AL sometimes } & \multicolumn{2}{|l|}{ No AL } & \multirow[b]{2}{*}{$p$ Value } \\
\hline & Number & (\%) & Number & (\%) & Number & (\%) & \\
\hline $\begin{array}{l}\text { Non-severe physical } \\
\text { Severe physical } \\
\text { Sexual } \\
\text { Emotional } \\
\text { Financial } \\
\text { Any of above }\end{array}$ & $\begin{array}{l}88 \\
54 \\
25 \\
199 \\
57 \\
217\end{array}$ & $\begin{array}{l}(12.2) \\
(7.3) \\
(3.5) \\
(27.9) \\
(8.0) \\
(30.5)\end{array}$ & $\begin{array}{l}82 \\
51 \\
26 \\
193 \\
51 \\
203\end{array}$ & $\begin{array}{l}(11.1) \\
(6.7) \\
(3.6) \\
(26.4) \\
(6.9) \\
(27.8)\end{array}$ & $\begin{array}{l}552 \\
265 \\
99 \\
1257 \\
241 \\
1392\end{array}$ & $\begin{array}{l}(7.7) \\
(3.6) \\
(1.4) \\
(17.7) \\
(3.4) \\
(19.6)\end{array}$ & $\begin{array}{l}<0.0001 \\
<0.0001 \\
<0.0001 \\
<0.0001 \\
<0.0001 \\
<0.0001\end{array}$ \\
\hline
\end{tabular}




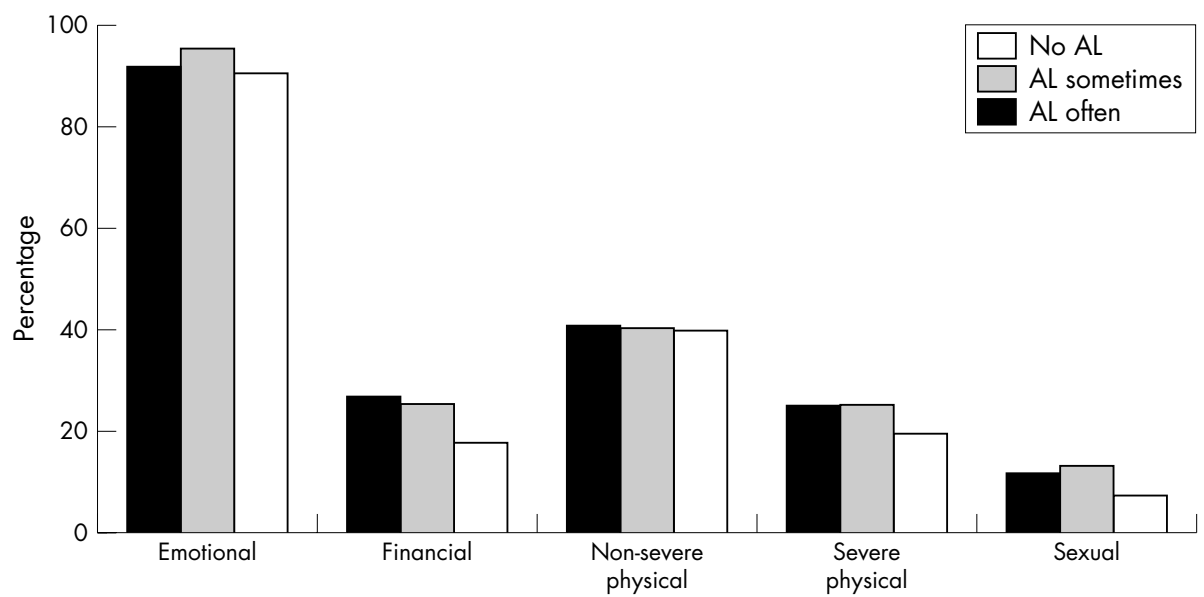

Figure 1 Type and frequency of IPV (emotional, financial, non-severe physical, severe physical, or sexual violence (see text for definitions)) among women who reported IPV by AL often, sometimes, or no AL.

residence, urban compared with rural residence and the number of household members receiving income from other sources.

\section{Type and severity of IPV}

There were no statistically significant differences in the rates of IPV between women with AL often and sometimes. The prevalence of all types of IPV was significantly higher in women with AL (whether often or sometimes) compared with women with no AL (table 2). Women with AL (often or sometimes) were more likely to experience any abuse (physical, sexual, emotional, or financial) compared with women with no AL $(p<0.0001)$. The unadjusted odds ratio (OR) for any IPV among women with AL often was 1.81 (95\% confidence interval $(95 \%$ CI) $1.49,2.19)$ and was 1.58 (95\% CI: 1.30, 1.92) for women with AL sometimes compared with women with no AL. For different types of IPV, the prevalence was also higher in women with $\mathrm{AL}(\mathrm{p}<0.0001)$.

We assessed the type of IPV and the severity of physical violence reported among the 2076 women who experienced any IPV in the previous five years (fig 1). Among these, more women with AL (often or sometimes) reported experiencing

\begin{tabular}{|c|c|c|}
\hline \multirow[b]{2}{*}{ Factor } & \multicolumn{2}{|l|}{ Any IPV } \\
\hline & Odds ratio & $(95 \% \mathrm{Cl})$ \\
\hline \multicolumn{3}{|l|}{ Activity limitation } \\
\hline Never & reference & \\
\hline Often & 2.12 & $(1.64,2.74)$ \\
\hline Sometimes & 1.79 & $(1.40,2.29)$ \\
\hline \multicolumn{3}{|l|}{ Aboriginal } \\
\hline No & reference & \\
\hline Yes & 2.11 & $(1.36,3.29)$ \\
\hline Age (per 10 year increase) & 0.80 & $(0.74,0.87)$ \\
\hline \multicolumn{3}{|l|}{ Marital status } \\
\hline Married/common law & reference & \\
\hline Divorced/separated/widowed & 7.20 & $(5.93,8.75)$ \\
\hline Single & 7.09 & $(5.32,9.45)$ \\
\hline \multicolumn{3}{|l|}{ Education of respondent } \\
\hline University or college graduate & reference & \\
\hline High school graduate & 1.17 & $(0.99,1.39)$ \\
\hline \multirow{3}{*}{\multicolumn{3}{|c|}{$\begin{array}{l}\text { Children } 14 \text { years or less living in household } \\
\text { No }\end{array}$}} \\
\hline & & \\
\hline No & reference & \\
\hline Yes & 1.20 & $(1.01,1.42)$ \\
\hline \multicolumn{3}{|l|}{ Household income } \\
\hline$\$ 50000$ or more & reference & \\
\hline No income- $\$ 29999$ & 1.46 & $(1.17,1.82)$ \\
\hline$\$ 30000-\$ 49999$ & 1.21 & $(1.00,1.47)$ \\
\hline \multirow{2}{*}{\multicolumn{3}{|c|}{ Years living in current dwelling }} \\
\hline & & \\
\hline$\geqslant 5$ & reference & \\
\hline$<5$ & 1.44 & $(1.23,1.68)$ \\
\hline \multicolumn{3}{|l|}{ Religious attendance } \\
\hline less than once/week & Reference & \\
\hline Once/week or more & 0.84 & $(0.70,1.00)$ \\
\hline \multirow{2}{*}{\multicolumn{3}{|c|}{$\begin{array}{l}\text { Source of income in past } 12 \text { months } \\
\text { Employment/self employment }\end{array}$}} \\
\hline Employment/self employment & reference & \\
\hline Other sources & 0.78 & $(0.63,0.96)$ \\
\hline No income & 0.75 & $(0.58,0.98)$ \\
\hline
\end{tabular}




\section{Key points}

- This study provides empirical data to support the claims that women with activity limitations are especially vulnerable to abuse. Women reporting activity limitations were more likely to report intimate partner violence than women reporting no activity limitations.

- Among women reporting any intimate partner violence, those with activity limitations reported higher rates of financial abuse, sexual violence, and severe physical violence than women without activity limitations.

- After taking into consideration differences in sociodemographic factors (for example, age, income, education), women reporting activity limitations were still more likely to experience violence than women with no activity limitations.

financial abuse by a current or former partner $(26.4 \%, 25.2 \%$ compared with $17.4 \%, \mathrm{p}<0.001)$ and sexual abuse $(11.5 \%$, $12.9 \%$ compared with $7.2 \%, \mathrm{p}<0.01)$ than women with no AL. Women with AL (often and sometimes) were more likely to experience severe physical violence than women with no $\operatorname{AL}(24.8 \%, 24.9 \%$ compared with $19.2 \%, p=0.02)$. We found no difference between women with AL and women with no $\mathrm{AL}$ in their experience of non-severe forms of physical abuse (40.6\%, 40.2\% compared with $39.7 \%, p=0.38$ ) or emotional abuse $(91.4 \%, 95.1 \%$ compared with $90.3 \%, p=0.09$ ) by a current or former partner. There were no significant differences in the types of IPV experienced among women with AL often and women with AL sometimes.

\section{Characteristics of respondents and rate of IPV}

For the logistic regression model, visible minority status was excluded because of collinearity concerns (highly correlated with place of birth). In the final logistic regression model (table 3), we adjusted for Aboriginal status, age, marital status, education, region of Canada, years living in current dwelling, presence of young children in the household, annual household income, source of income, and whether other household members received income.

After adjustment, the odds of experiencing "any IPV" by a current or former partner in the previous five years remained greater for women with AL often (OR $=2.12 ; 95 \% \mathrm{CI}$ : 1.64 , 2.74) and women with AL sometimes (OR $=1.79$; $95 \% \mathrm{CI}$ : $1.40,2.29)$ compared with women with no AL.

\section{DISCUSSION}

Assessing the prevalence of IPV among women with AL is an essential first step in determining the health consequences of abuse, estimating the costs to the health care system, and developing and evaluating prevention strategies. Results from our study show that the prevalence of physical, sexual, emotional, and financial IPV is significantly higher in women with AL when compared with women with no AL. After adjusting for various sociodemographic factors, women with AL had about twice the odds of experiencing IPV compared with women with no AL. In addition, among women who experienced any IPV in the previous five years, women with AL were more likely to experience financial and sexual abuse and severe forms of physical abuse by an intimate partner.

Many ethical and humanitarian questions are raised by these results. Essentially, why are women with physical and mental difficulties additionally burdened by their experience of abuse? We found that women with AL were older, had lower incomes, and less education than women without AL. These factors may also limit the choices available to women with AL. In this cross sectional study, we were not able to determine if abuse led to the AL (physical injury) or if women with AL were more likely to be abused. It is however more likely to be the latter as women with $\mathrm{AL}$ are more dependent upon their partners. ${ }^{13}$

Although some sociodemographic differences existed between women reporting AL often and women reporting AL sometimes, the rate of IPV among these two groups was similar. Where sociodemographic differences did exist, the pattern for those women reporting AL sometimes was closer to those reporting AL often than to the pattern seen among women with no AL. It is possible that a respondent's interpretation of how often an AL was experienced (that is, often compared with sometimes) varied, so that there may be overlap between the two groups. The finding of no difference in the rates of IPV between women reporting AL often and women reporting AL sometimes suggests that the presence of $\mathrm{AL}$ in itself is a risk factor for IPV. None the less, it is important to examine the aftermath of IPV for women with AL often compared with sometimes, as the latter may have fewer barriers (physical or financial) to leaving the abuser.

In our study, AL was broadly defined to include physical or mental conditions or health problems and differs from the concept of disability used in previous studies. AL may include a wider range of health problems than is currently considered in a "disabled" group. Some previous literature on women with disabilities has suggested that women with disabilities may be more vulnerable to abuse because of factors relating to specific disabilities. ${ }^{14} 15$ For example, women who are limited in physical strength and mobility are vulnerable to physical abuse that entails confinement or physical restraint. Similarly, assistance with activities necessary for daily living can be withheld in exchange for sexual activities. ${ }^{16}$ Including disability specific questions, which take these factors into account, has been shown to detect higher rates of abuse. ${ }^{17}$ The GSS was not designed to address the issue of disability in itself so questions assessing caregiver abuse were not included and we could therefore not ascertain if these were the same issues for women with AL. Disability is not precisely the same concept as activity limitations; the former encompasses impairments in body functions, limitations in activities, and restrictions in social participation. Thus persons with disabilities have limitations in their activities, but not all persons with activity limitations are disabled. More research is needed to determine if the risk of IPV for women with disabilities and AL is the same.

The large sample enabled us to provide better precision for the estimates of abuse and the five year time frame for reporting abuse probably minimised difficulties in recall of important events. As well, the large sample enabled us to identify important associations with IPV. Our study was community based, thus encompassing a wider range of women than previous studies of institutionalised women. It

\section{Policy implications}

The relation between activity limitations and disability needs to be more fully examined and elucidated. A high prevalence of intimate partner violence among women with activity limitations highlights the need to develop effective health and social care intervention strategies for these women. Future research should be directed to examine the effect of abuse on the health of women with activity limitations, and the role of the health care system in reducing abuse among this already vulnerable group of women. 
is probable that the risk of abuse for institutionalised women with mental or physical health problems would be even greater.

There are some limitations to this study. Firstly, given the sensitive nature of IPV, respondents may have been reluctant to report abuse. In such a case, the prevalence of IPV may have been underestimated. Despite this, we consistently saw higher rates of violence among those reporting AL. While it is possible that women with AL were more likely to report IPV than women without $\mathrm{AL}$, the reason for such theoretical over-reporting is not known.

Secondly, the GSS focused on experiences of violence within the past five years from the date of the survey and did not assess lifetime rates. This is both a strength and a limitation, as a shorter time frame may have reduced recall problems but did not permit a determination of patterns of longer term abuse. It is possible that women were unable to recall the exact time the abuse occurred and as a result, may have reported on abuse that occurred outside the five year time frame. Thirdly, respondent characteristics were asked in current time and the abuse was asked about in the recent past. Thus variables such as marital status, income, may have changed over the five year time frame and may not necessarily have been the same as at the time of the abuse. Presumably there would be little change in these characteristics for most respondents but unless a longitudinal design is used to study abuse, we must be cautious about interpreting the relation between current sociodemographic variables and abuse in the past. Finally, it should be noted that this community dwelling population based study did not include those who did not speak English or French, those unable to respond to a survey, persons living in the Northern Territories, the homeless, and those living in institutions. These groups may be at particular risk for violence or AL, or both, but we were unable to assess them in this study.

Our findings call for increased recognition of the issue of violence that occurs in the lives of people with AL. Our study suggests that abuse among those reporting $\mathrm{AL}$ is high and provides empirical data of the extent of abuse against women with health related difficulties. Women with AL represent a high risk group to be targeted in terms of IPV prevention and intervention. Much more needs to be known about the effect of abuse on the health of women with $\mathrm{AL}$, and the role of the health care system in reducing abuse among this already vulnerable group of women. Women with AL visit health care professionals more often than women without AL, thus providing an opportunity to uncover abuse. Currently, the issue of systematic screening for abuse by health care professionals is being actively debated; however, routine screening has been endorsed by many influential international organisations such as the International Federation of Gynecology and Obstetrics. ${ }^{13}$ As abuse is associated with poor health, the increased risk of abuse in this group of women has implications for health care utilisation. More research is needed to identify the causes and risk factors associated with IPV among women with AL.

\section{Authors' affiliations}

M M Cohen, T Forte, J Du Mont, I Hyman, S Romans, Centre for Research in Women's Health, Sunnybrook and Women's Health Sciences Centre, University of Toronto, Toronto, Canada

M M Cohen, Department of Health Policy, Management and Evaluation, University of Toronto

I Hyman, Department of Public Health Sciences, University of Toronto

S Romans, Department of Psychiatry, University of Toronto

Funding: this research was supported by a grant from the Canadian Institutes of Health Research, Institute of Gender and Health, and the Atkinson Foundation. Dr Du Mont is the recipient of an Investigator Award from the Canadian Institutes of Health Research. Dr Romans is the Shirley Brown Chair in Women's Mental Health, Sunnybrook and Women's Health Sciences Centre.

Conflicts of interest: none declared.

\section{REFERENCES}

1 Fischbach RL, Herbert B. Domestic violence and mental health: correlates and conundrums within and across cultures. Soc Sci Med 1997;45:1161-76.

2 McCauley J, Kern DE, Kolodner K, et al. Relation of low-severity violence to women's health. J Gen Intern Med 1998;13:687-91.

3 Coker AL, Smith PH, Bethea L, et al. Physical health consequences of physical and psychological intimate partner violence. Arch Fam Med 2000;9:451-7.

4 Krantz G, Ostergren PO. The association between violence victimisation and common symptoms in Swedish women. J Epidemiol Community Health 2000;54:815-21.

5 Nosek MA, Howland CA, Young ME. Abuse of women with disabilities: policy implications. J Disabil Polic Stud 1997;8:157-75.

6 Andrews AB, Veronen $\sqcup$. Sexual assault and people with disabilities. J Soc Work Hum Sexuality 1993;8:137-59.

7 Ustun TB, Chatterii S, Bickenbach J, et al. The international classification of functioning, disability and health: a new tool for understanding disability and health. Disabil Rehabil 2003;25:565-71.

8 Norris DA, Paton DG. Canada's general social survey: rive years of experiences. Survey Methodology 1991;17:227-40.

9 Johnson H, Bunge VP. Prevalence and consequences of spousal assault in Canada. Can J Criminol 2001;43:27-45.

10 Straus M. Measuring intrafamily conflict and violence: the conflict tactics scales. J Marriage Fam 1979;41:75-88.

11 Straus MA, Hamby SL, Boney-McCoy S, et al. The revised conflict tactics scales (CTS2). J Fam Issues 1996;17:283-316.

12 Statistics Canada. 1999 General social survey, cycle 13. Victimization: public use microdata file documentation and user's guide. Ottawa: Minister of Industry, 2000

13 Nosek MA, Hughes RB, Taylor HB, et al. Violence against women with disabilities: the role of physicians in filling the treatment gap. In: Welner SL, Haseltine F, eds. Welner's guide to the care of women with disabilities. Philadelphia: Lippincott Williams and Wilkins, 2004:333-45.

14 Chenoweth L. Violence and women with disabilities. Violence Against Women 1996;22:391-411.

15 Chang JC, Martin SL, Moracco KE, et al. Helping women with disabilities and domestic violence: strategies, limitations, and challenges of domestic violence programs and services. J Womens Health 2003;12:699-708.

16 Nosek MA, Foley CC, Hughes RB, et al. Vulnerabilities for abuse among women with disabilities. Sex Disabil 2001;19:177-89.

17 McFarlane J, Hughes RB, Nosek MA, et al. Abuse assessment screen-disability (AAS-D): measuring frequency, type, and perpetrator of abuse toward women with physical disabilities. J Women Health Gen-B 2001;10:861-6. 